\title{
The Use of Children's Literature With University English as a Foreign Language Learners in Taiwan
}

\author{
Cheng-Fang Huang \\ Ming Chuan University, Taipei, Taiwan
}

\begin{abstract}
This paper reports findings from a longitudinal qualitative study that investigated the use of children's literature for Taiwanese University English as a Foreign Language (EFL) students' reading. During the course of their sophomore year, 17 students participated and each student held two to seven individual reading sessions, to which they brought a self-selected children's picture storybook or children's novel they had finished reading on their own and orally read it to the researcher. Their oral reading and the discussion of each book with the researcher were audio recorded. To gain insight into the reading progress, these oral data were categorized and analyzed in terms of mispronunciation patterns, misunderstanding of vocabulary, misinterpretation of sentence or passage, and researcher's guidance. General findings of the 17 participants were presented in three categories: (1) vocabulary acquisition, (2) common comprehension problems, and (3) common pronunciation problems. Further analysis of two motivated students who read five to seven books revealed that (1) these two EFL learners gradually developed conscious awareness of their own pronunciation and comprehension errors and (2) they progressively acquired better competence to apply the pronunciation tips and reading comprehension techniques provided by the researcher during previous sessions. These findings and corresponding implications are discussed and further research suggestions are made.
\end{abstract}

Keywords: English as a Foreign Language (EFL) learners, reading progress, children's literature, miscue analysis

\section{Introduction}

Reading has been an essential component in language learning, no matter first language (L1) or second language (L2). It has been observed that students' motivation to read in an L2 is not always congruent with that toward their L1. Some motivated readers in the L1 were found to be not as motivated to read in the L2 (Takase, 2007). Among the four critical factors, reading materials, reading abilities, attitudes, and sociocultural environment, Day and Bamford (1998) asserted that reading materials and attitudes are the most prominent ones influencing students' motivation to read in the L2.

Mori (1999) studied the reading habits of university students and found that other than the concern of grades, the amount of reading students would engage in was affected by the reading material. To enhance language learners' motivation to read in the L2, Leung (2002) suggested educators to provide interesting materials at an appropriate level of difficulty. This suggestion corresponded to the fundamental elements in input hypothesis (Krashen, 1985) and pleasure hypothesis (Krashen, 2004). According to Krashen (1989), language learners would better acquire languages by comprehending the input message in a lower anxiety

Cheng-Fang Huang, assistant professor, Ed.D., English Language Center, Ming Chuan University. 
context. Specifically, the more comprehensible aural and written input is provided, the more language acquisition occurs. Research evidence showed that when unknown word densities exceeded 5\%, reading became strenuous and comprehension suffered (Laufer, 1989). In many extensive reading programs supporting Krashen's hypothesis, L2 learners choose reading materials that are at appropriate comprehension level for them. Krashen's (2004) pleasure hypothesis further proposed that educational activities which help language acquisition are those that are enjoyable.

Extensive reading is "an approach to the teaching and learning of second language reading in which learners read large quantities of books and other materials that are well within their linguistic competence" (Day \& Bamford, 1998, p. viii). Richards and Schmidt (2002) pointed out that

extensive reading means reading in quantity and in order to gain a general understanding of what is read. It is intended to develop good reading habits, to build up knowledge of vocabulary and structure, and to encourage a liking for reading. (pp. 193-194)

Prior research on extensive reading has shown promising learning benefits for L2 learners on various aspects including vocabulary acquisition (Nation, 2001), reading comprehension (Bell, 2001), reading fluency (Bell, 2001; Kusanagi, 2004), the development of good reading habits (Nash \& Yuan, 1992), and writing ability (Hafiz \& Tudor, 1990; Krashen, 1989; Tsang, 1996). In addition, students became more confident and motivated as L2 readers (Day \& Bamford, 1998; Mason \& Krashen, 1997).

Krashen $(1989,2004)$ and supporters have asserted that reading freely and extensively is a key factor contributing to vocabulary development for both L1 and L2 readers. Krashen (1993) further argued that comprehensible input accompanied with incidental learning sufficiently facilitate the improved L2 proficiency in areas such as vocabulary, grammar, reading comprehension, spelling, and writing style. In contrast, Cobb (2008) pointed out that

the adequacy of free reading is an idea with high credibility in the time frame of L1 acquisition, and some credibility in an extended time frame of L2 acquisition under conditions of exceptional motivation. But carried into the typical time frame of instructed L2 acquisition, it is an idea that grossly misrepresents the problems faced by L2 readers who need to read to learn in their second languages. For these learners, an adequate second lexicon will not happen by itself; it will be provisioned through well-designed instruction including but not limited to reading. (p. 113)

Similarly, Norris and Ortega (2000) studied the effects of various types of instructions and concluded that explicit instruction is more efficient than implicit instruction to facilitate L2 acquisition.

\section{Method}

\section{Implementation of Storybook Reading}

The major principle suggested by Day and Bamford (2002) to implement extensive reading are: (1) The reading material should be easy for the learners; (2) there should be a variety of reading material on a wide range of topics available for the learners; (3) learners should be given the freedom to choose what they would read; (4) learners would be reading as much as possible; and (5) the purpose of reading should be mainly for pleasure, information, and general understanding.

In the beginning of the school year, students were informed of the opportunity to gain extra credits for the required English as a Foreign Language (EFL) course by participating in storybook reading outside the classroom. From the library or from the researcher, they could check out a book that was at the appropriate 
level and interesting for them to read. The book could be children's picture storybook, children's novel, young adult novel, or a novel. After reading the book on their own, they would need to orally read the whole picture storybook or one randomly assigned chapter from a novel aloud to the researcher to gain extra credits. The researcher would listen and intermittently check the student's comprehension regarding vocabulary, phrases, sentences, or a passage. Explicit instruction on the pronunciation principles and better comprehension were given tailored to the student's performance. At the end of each read-aloud section, the researcher would summarize the student's strength and weakness and give further suggestions.

\section{Participants}

Seventeen sophomore students from four different majors, business management, international business, mass communication, and accounting, participated in this storybook reading study. All the students in this study had learned English for seven years since junior high school. However, the English proficiency among participants was heterogeneous; therefore, the books chosen by the participants ranged from 300-word picture storybook to 170-page children's novel. Students were encouraged to read as many books as they could, but were also given the freedom to do the read-aloud at their own convenience. Under such circumstances, most participants managed to read only two to three storybooks. Two very motivated students, Sandy and Emma, managed to read five to seven storybooks or novels. Their progress were, therefore, more significant than the others.

\section{Data Collection and Analysis}

Each read-aloud session lasted for 20 to 30 minutes and was audio recorded. The recording was then transcribed and analyzed using miscue analysis. Miscue analysis was originally developed by K. Goodman (1973) for the purpose of understanding the reading process by evaluating, categorizing, and explaining the miscue phenomena found to be prevalent in each reader. In addition, to provide a way to gain insight into the reading process through analyzing the oral reading of individual students, miscue analysis can also provide specific information about a student's reading ability. Through miscue analysis, specific and repetitive problems of each and across participants were identified.

\section{Findings}

The findings from the general observation and miscue analysis of the 17 participants were threefold: (1) vocabulary acquisition, (2) common comprehension problems, and (3) common pronunciation problems. First of all, from a picture storybook, the average gain of vocabulary was 15 to 30 words; from a children's novel, the average gain of vocabulary was 10 to 20 new words per chapter. Surprisingly, some of the words could be simple but students have never been exposed to (e.g., bunny, hare, supper, rescue, nightmare, chase, sail). Secondly, students often misinterpreted the meaning of a multiple meaning word, such as wind, cry, school, etc. They also had more comprehension problems with cultural related term, such as bobbing for apple, playing tag, piggy in the middle, and so on. Thirdly, the most common mispronunciation was associated with the -ed ending of verbs. It was quite difficult for most participants to correctly distinguish when to pronounce it /t/, /d/, /Id/. In addition, the pronunciation of vowel teams, such as ea (e.g., read-read-read, mean-meant-meant, pear vs. pearl), and the insertion of consonant $\mathrm{n}, \mathrm{r}$, and silent $\mathrm{t}$, silent $\mathrm{b}$ and the mispronunciation of consonant $\mathrm{n}$ and $\mathrm{l}$ were the more commonly made mistakes. 


\section{Progress of Sandy}

Sandy, a business management major aware of her limited English proficiency, was very willing to devote extra time to improve English and thus read a total of seven picture storybooks. She could not fully understand English questions the researcher asked nor respond in English; thus the discussions after oral reading were carried out in both English and Chinese. The first four books she read were picture storybooks for 3 to 8 -year-old children and the last three were for 5 to 9 -year-olds. Her reading rate of the first book was $60.6 \mathrm{wpm}$ (words per minute) with constant pauses at each unfamiliar word; gradually the rate increased to 74.8 wpm with almost no pauses. Mispronunciation was decreased from 70 out of 741 words $(9.45 \%)$ to 36 out of 855 words (4.2\%). Vocabulary comprehension of randomly checked words was increased from $38.1 \%$ to $66.7 \%$.

\section{Progress of Emma}

Emma, a mass communication major with intermediate English proficiency, was also very willing to devote extra time to enhance English and thus read a total of one picture storybook and four children's novel. She read with very good pronunciation and intonation. She was able to understand English questions the researcher asked and respond clearly in English; thus the reading sessions were conducted mainly in English. The first picture storybook she chose was for 3 to 8 -year-old children with her favorite theme, kitten. Realizing that picture storybook was too easy for her, she moved on, with the suggestions of the researcher, to read four children's novels targeted for age 8-12. Her reading rate of the first novel was $107 \mathrm{wpm}$; gradually the rate increased to $114 \mathrm{wpm}$. Mispronunciation was decreased from 19 out of 683 words (2.8\%) to 13 out of 540 words $(2.4 \%), 22$ out of 961 words $(2.2 \%), 10$ out of 496 words $(2.0 \%)$ respectively. Vocabulary comprehension of randomly checked words was increased from $60 \%$ to $85.7 \%$.

\section{Conclusion}

The one-on-one reading sessions allowed the researcher to pinpoint each learner's specific strength and weakness and to provide individualized feedback and guidance. The type of guidance provided included correct pronunciation, explain phonics rules, guide the learner to better comprehend a word, a phrase, or a sentence through the context, demonstrate how to choose correct meaning of a word from the dictionary, and demonstrate how to google the meaning of a phrase. The two participants, Sandy and Emma, who read more books than the others, showed more conscious awareness of their own pronunciation and comprehension errors and demonstrated more self-corrections. In the year-long process, they progressively acquired better competence to apply the pronunciation tips and comprehension techniques provided by the researcher from their previous reading sessions. The findings of this study suggested that with appropriate materials that interest the learner and with the guidance tailored to the learner's individual needs, the EFL learners' reading could show positive progress. More research needs to be conducted on individual-scale as well as on more large-scale to gain more insight into EFL learners' reading progress.

\section{References}

Bell, T. (2001). Extensive reading: Speed and comprehension. The Reading Matrix, 1(1), 1-13.

Cobb, T. (2008). Commentary: Response to McQuillan and Krashen. Language Learning and Technology, 12(1), $109-114$.

Day, R. R., \& Bamford, J. (1998). Extensive reading in the second language classroom. Cambridge: Cambridge University Press.

Day, R., \& Bamford, J. (2002). Top ten principles for teaching extensive reading. Reading in a Foreign Language, 14, $136-141$.

Goodman, K. (1973). Miscue analysis: Applications to reading instruction. Urbana, IL: ERIC Clearinghouse on Reading and Communication Skills and National Council of Teachers of English. 
Hafiz, F. M., \& Tudor, I. (1990). Graded readers as an input medium in L2 learning. System, 18, 31-42.

Krashen, S. D. (1985). The input hypothesis: Issues and implications. New York: Longman.

Krashen, S. D. (1989). We acquire vocabulary and spelling by reading: Additional evidence for the input hypothesis. The Modern Language Journal, 73, 440-464.

Krashen, S. D. (1993). The power of reading: Insights from the research. Englewood, CO: Libraries Unlimited.

Krashen, S. D. (2004). The power of reading: Insights from the research (2nd ed.). Portsmouth, NH: Heinemann.

Kusanagi, Y. (2004). The class report 2: Course evaluation of Pleasure Reading Course. The Journal of Rikkyo University Language Center, 11, 29-42.

Laufer, B. (1989). What percentage of text-lexis is essential for comprehension? In C. Lauren \& M. Nordman (Eds.), Special language: From humans thinking to thinking machines (pp. 316-323). Clevedon, UK: Multilingual Matters.

Leung, C. Y. (2002). Extensive reading and language learning: A diary study of a beginning learner of Japanese. Reading in a Foreign Language, 14, 66-81.

Mason, B., \& Krashen, S. D. (1997). Extensive reading in English as a foreign language. System, 24, 91-102.

Mori, S. (1999). The role of motivation in the amount of reading. Temple University Japan Working Papers in Applied Linguistics, 14, 51-68.

Nash, T., \& Yuan, Y. (1992). Extensive reading for learning and enjoyment. TESOL Journal, 2, 27-31.

Nation, P. (2001). Learning vocabulary in another language. Cambridge: Cambridge University Press.

Norris, J. M., \& Ortega, L. (2000). Effectiveness of L2 instruction: A research synthesis and quantitative metaanalysis. Language Learning, 50, 417-528.

Richards, J. C., \& Schmidt, R. (Eds.). (2002). Longman dictionary of language teaching and applied linguistics (3rd ed.). London: Longman.

Takase, A. (2007). Japanese high school students' motivation for extensive L2 reading. Reading in a Foreign Language, 19(1), $1-18$.

Tsang, W. (1996). Comparing the effects of reading and writing on writing performance. Applied Linguistics, 17, $210-233$.

\section{Appendix A: Oral Reading Script Sample}

Sandy: Book 1-Alexander and the Wind-Up Mouse by Leo Lionni

Reading Rate: 741 word $/ 729 \mathrm{sec}=1.01 \mathrm{word} / \mathrm{sec}=60.6 \mathrm{wpm}$

Purple: Teacher

Black: Student-Correct Pronunciation and Translation

Red: Student-Mispronunciation and Mistranslation

$/:<0.5 \mathrm{sec}$ pause $(\mathrm{p}): 0.5 \mathrm{sec}$ pause $(1 \mathrm{sec} \mathrm{P}): 1 \mathrm{sec}$ pause

00:06-00:35 (30 sec)

0101 "Help! Help! A mouse!” There was a (1 sec P) scream. Then a crash (crush).

0102 Cups, (1.5 sec uhnn) saucers, and spoons were (wa, where) flying in all (in a, in all) directions.

0103 Alexander (A-li-san) ran for his hole/as fast as his little/legs would carry him.

\section{After Reading Interaction}

1. T Correction: Alexander

2. Check Meaning: spoons (v)saucers (x)(T gives correct translation)

crash (falling, something is falling ( $\mathrm{T}$ gives context clue)

(T's contextual guidance: What would happen when you see a mouse?)

3. $\mathrm{S}$ ask $\mathrm{T}$ for pronunciation: Alexander

4. Translation: Alexander ran for his hole as fast as his little legs would carry him.

$\mathrm{S}$ : This mouse, he ran with his little legs, the legs carry him, ran away very fast 
$\mathrm{T}$ : he did his best to run as fast as he could

02:18-02:35 (18 sec)

0201 All Alexander wanted (went) was a few (p) crumbs (croo, croombs) and yet

0202 every time they saw him/they would (p) scream for help

0203 or $(\mathrm{p})$ chase him with a $(1 \mathrm{sec} \mathrm{P})$ broom.

\section{After Reading Interaction}

1. Check Meaning: broom ( $8 \mathrm{sec} \mathrm{P}$ T: look at the picture S points to broom) crumb (x)(T gives context clue)(T demonstrates and guides: from a bread, when you're eating a bread,... S: wanting to eat... T: you'll have some crumbs on the... S: .oh, that...crumbs!)

2. T Correction: wanted crumbs (silent b) (T: ' $u$ ' as in the bus)

\section{Appendix B: Miscue Analysis Sample}

Sandy: Book 1-Alexander and the Wind-Up Mouse by Leo Lionni

Reading Rate: $741 \mathrm{word} / 729 \mathrm{sec}=1.01 \mathrm{word} / \mathrm{sec}=60.6 \mathrm{wpm}$

Table B1

Mispronunciation (Excluding Self-corrected Ones)

\begin{tabular}{|c|c|c|c|c|}
\hline No. & Text & Reader & Line & Teacher's Help \\
\hline 1 & crash & crush & 0101 & \\
\hline 2 & were & wa, where & 0102 & \\
\hline 3 & Alexander & A-li-san & 0103 & Correction \\
\hline 4 & wanted & went & 0201 & Correction \\
\hline 5 & crumbs & croo, croombs & 0201 & $\begin{array}{l}\text { Correction; } \\
\text { Explanation: "u" Pronunciation }\end{array}$ \\
\hline 6 & sneaked & sneakd, sneak-d & 0302 & Indirect Demo (via Check Meaning) \\
\hline 7 & ordinary & ordi-NA-ry & 0303 & Correction \\
\hline 8 & himself & Himself-s & 0303 & \\
\hline 9 & instead & in-stare & 0303 & Indirect Demo (via Check Meaning) \\
\hline 10 & wheels & whe, whis & 0303 & Correction \\
\hline 11 & back & bake & 0304 & \\
\hline 12 & Willy & Welly & 0401 & \\
\hline 13 & wind-up & wend-up; wide up & 0401 & Correction \\
\hline 14 & cuddle & cu, cud & 0402 & Correction \\
\hline 15 & at & ate & 0402 & \\
\hline 16 & pillow & pi-ow & 0403 & Correction \\
\hline 17 & teddy & tidy & 0403 & \\
\hline 18 & bear & beer & 0403 & \\
\hline 19 & loves & loves, love & 0404 & \\
\hline 20 & Alexander & A-lixander & 0405 & \\
\hline 21 & friend & friend-s & 0406 & \\
\hline 22 & everyone & everyone, everybody & 0408 & \\
\hline 23 & Alexander & A-lixander & 0501 & \\
\hline 24 & mousetrap & mouse-trip & 0502 & Double Check \\
\hline 25 & penguin & penground & 0503 & \\
\hline 26 & bear & beer & 0504 & \\
\hline
\end{tabular}


(Table B1 continued)

\begin{tabular}{|c|c|c|c|c|}
\hline No. & Text & Reader & Line & Teacher's Help \\
\hline 27 & Alexander & A-lixander & 0603 & \\
\hline 28 & thought & tought & 0603 & \\
\hline 29 & Why & What & 0605 & \\
\hline 30 & wind-up & wide-up & 0606 & \\
\hline 31 & heard & hear-d & 0701 & Correction; Demo \\
\hline 32 & mysteriously & mys-TER-ris & 0701 & Correction \\
\hline 33 & the (+vowel) & the $(+$ consonant $)$ & 0702 & \\
\hline 34 & pebblepath & pablepath & 0702 & \\
\hline 35 & bush & push & 0703 & \\
\hline 36 & Alexander & Alixander & 0801 & \\
\hline 37 & whispered & whisper & 0802 & \\
\hline 38 & suddenly & $\begin{array}{l}\text { san-, sun-, san-den-c } \\
\text { sanderly }\end{array}$ & 0802 & $\begin{array}{l}\text { Correction; Pinpoint Problem } \\
\text { (T: Delete " } n \text { " Sound) }\end{array}$ \\
\hline 39 & colors & clouds & 0803 & \\
\hline 40 & wind-up & wide-up & 0804 & \\
\hline 41 & asked & asked, a-ask-k-d; ask & 0804 & Correction \\
\hline 42 & Alexander & Alizier; Alexiden & 0804 & Correction \\
\hline 43 & quivering & quo-vering & 0805 & Correction \\
\hline 44 & voice & voce & 0805 & $\begin{array}{l}\text { Correction; Pinpoint Problem } \\
\text { (T: Don't forget "i") }\end{array}$ \\
\hline 45 & pebble & per-pe-perple & 0806 & Correction \\
\hline 46 & searched & stre- & 0901 & Correction \\
\hline 47 & tired & tied & 1001 & \\
\hline 48 & hungry & hangry & 1001 & \\
\hline 49 & dumped & drum & 1008 & Pinpoint Problem (T: No "r") \\
\hline 50 & thrown & drow & 1008 & \\
\hline 51 & suddenly & sen-den-ly; seddenly & 1011 & $\begin{array}{l}\text { Pinpoint Problem (T: No "n"); Correction; Pinpoint Problem } \\
\text { (T: Not "e"); Explanation: (T: As "u" in "bus") }\end{array}$ \\
\hline 52 & excited & excite & 1101 & \\
\hline 53 & precious & - & 1101 & Correction \\
\hline 54 & bush & push & 1104 & \\
\hline 55 & The & he & 1105 & \\
\hline 56 & rustled & re, rus, rustly; rushely & 1105 & Correction \\
\hline 57 & round & roon & 1106 & Correction \\
\hline 58 & wish & wash & 1108 & \\
\hline 59 & suddenly & sunddenly & 1110 & \\
\hline 60 & blinked & blank; blanked & 1112 & Correction \\
\hline 61 & blinding & b- & 1112 & Correction \\
\hline 62 & light & lit & 1113 & Correction \\
\hline 63 & quiet & quit & 1113 & Correction \\
\hline 64 & alas & o- & 1301 & Correction \\
\hline 65 & empty & impy; empy & 1301 & Correction \\
\hline 66 & thought & tought & 1301 & \\
\hline 67 & a & the & 1302 & \\
\hline 68 & squeaked & s-quea & 1401 & \\
\hline 69 & Cautiously & - & 1401 & Correction \\
\hline 70 & hugged & hug-ged /id/ & 1502 & Correction; Explanation (-ed) \\
\hline
\end{tabular}

